\title{
Bacterial endocarditis, mitral regurgitation, and intra-atrial thrombosis following mitral valve replacement
}

\author{
HAR Y M. WINDSOR, PAUL FAGAN, AND \\ MARK X. SHANAHAN
}

From St. Vincent's Hospital, Sydney, Australia

\begin{abstract}
Bacterial endocarditis with positive blood culture occurred on six occasions in a series of 140 mitral valve replacements. In three of these, extensive detachment of the prosthesis with severe mitral incompetence resulted. Re-operation was undertaken in two of these cases. Intra-atrial thrombosis occurred twice. In three other cases, in which intra-atrial thrombosis occurred, infection was strongly suspected to have been the responsible factor. Mitral regurgitation presented no difficulty in diagnosis, as all patients had severe congestive cardiac failure and typical physical signs. Confirmation was established by cinéangiography. Intra-atrial thrombosis presented difficulty in diagnosis. A persistently positive blood culture, continued pyrexia, and a history of sepsis were the most consistent and significant findings in the cases reported. The antibiotic regime described by Amoury and his colleagues has been used for the past year. There has not been a single case of bacterial endocarditis, intra-atrial thrombosis, or wound infection in 120 consecutive valve replacements on this regime. Because of the high mortality associated with intra-atrial thrombosis, and the close association between endocarditis and thrombosis, the presence of endocarditis with or without regurgitation might well be a compelling reason for re-operation. The mortality from these complications could, we believe, be reduced by the use of a more extensive antibiotic cover and a more vigorous attitude to surgical intervention. We have not had to consider re-operation since adopting the policy outlined, as these complications have not occurred.
\end{abstract}

Bacterial endocarditis with positive blood culture occurred six times in 140 patients who underwent mitral valve replacement (see Table). In these six, mitral regurgitation and intra-atrial thrombosis had a significant incidence. In a further three cases, intra-atrial thrombosis was associated with infection, but positive blood cultures were not obtained.

The object of this paper is to correlate the various aspects of these complications.

\section{BACTERIAL ENDOCARDITIS ASSOCIATED WITH MITRAL REGURGITATION}

CASE 1 (R.M. 859) (Windsor and Shanahan, 1967) A man aged 43 had a heavily calcified mitral valve replaced on 12 August 1963. His post-operative course was uneventful. He was given sodium methicillin, $4 \mathrm{~g}$. daily for one week, and sodium cloxacillin, $1 \mathrm{~g}$. daily for two months, following operation.
T A B L E

BACTERIAL ENDOCARDITIS AND ASSOCIATED PHENOMENA

\begin{tabular}{|c|c|c|c|c|c|}
\hline $\begin{array}{l}\text { Case } \\
\text { No. }\end{array}$ & $\begin{array}{r}\text { Organism } \\
.\end{array}$ & Aetiology & $\begin{array}{c}\text { Intra-atrial } \\
\text { Throm- } \\
\text { bosis }\end{array}$ & $\begin{array}{c}\text { Mitral } \\
\text { Regurgi- } \\
\text { tation }\end{array}$ & Result \\
\hline 1 & $\begin{array}{c}\text { Staph. albus } \\
\text { coagulase- } \\
\text { negative }\end{array}$ & $\begin{array}{l}\text { ? Cardiac } \\
\text { catheteriza- } \\
\text { tion }\end{array}$ & + & + & $\begin{array}{l}\text { Alive and } \\
\text { well }\end{array}$ \\
\hline 2 & $\begin{array}{c}\text { Staph. aureus } \\
\text { coagulase- }\end{array}$ & $\begin{array}{l}\text { Empyema } \\
\text { thoracis }\end{array}$ & + & + & Died \\
\hline 3 & $\begin{array}{c}\text { posttive } \\
\text { Staph. albus } \\
\text { coagulase- } \\
\text { negative; } \\
\text { Staph. } \\
\text { aureus } \\
\text { coagulase- } \\
\text { positive }\end{array}$ & $\begin{array}{l}\text { Calcific } \\
\text { remnant } \\
\text { in mitral } \\
\text { annulus }\end{array}$ & + & + & Died \\
\hline 4 & $\begin{array}{l}\text { Staph. albus } \\
\text { coagulase- } \\
\text { negative }\end{array}$ & $\begin{array}{l}\text { Empyema } \\
\text { thoracis }\end{array}$ & + & - & Died \\
\hline 5 & $\begin{array}{c}\text { Staph. aureus } \\
\text { coagullase- }\end{array}$ & Unknown & + & - & Died \\
\hline 9 & $\begin{array}{l}\text { Staph. albus } \\
\text { coagulase- } \\
\text { negative }\end{array}$ & $\begin{array}{l}? \text { Calcific } \\
\text { remnant in } \\
\text { mitral } \\
\text { annulus }\end{array}$ & ? & $?$ & $\begin{array}{l}\text { Died; } \\
\text { necropsy } \\
\text { refused }\end{array}$ \\
\hline
\end{tabular}


Twelve months after surgery at the time of routine cardiac catheterization he had a virtually normal exercise tolerance, no evidence of cardiac failure, and no abnormal cardiac murmurs. His pulmonary artery pressure was $38 / 12 \mathrm{~mm}$. $\mathrm{Hg}$ at rest and $84 / 48 \mathrm{~mm}$. $\mathrm{Hg}$ on exercise, compared with a resting pulmonary artery pressure of $90 / 50 \mathrm{~mm}$. $\mathrm{Hg}$ prior to operation.

Two months after this procedure he developed fulminating bacterial endocarditis. Blood cultures grew coagulase-negative Staphylococcus albus. Following treatment with sodium methicillin, $12 \mathrm{~g}$. daily for four weeks, he made a good recovery and was discharged on 10 December 1964.

Three months later he presented in severe cardiac failure with pulmonary oedema. A soft mitral systolic murmur was heard. Blood cultures at this time were negative, but deterioration was rapid, and anasarca developed. On 24 March 1965 he was again catheterized: the pulmonary artery pressure was 160 $\mathrm{mm}$. Hg. The prosthesis was abnormally mobile, displaying a rocking movement on fluoroscopy. Gross mitral regurgitation was seen on cinéangiography.

Operation was carried out on 29 March 1965 as an emergency measure. The left atrium was reexplored through a right antero-lateral thoracotomy. The prosthesis was found to be detached along the entire length of the mural aspect of the mitral annulus, and there was some soft thrombus present. All the sutures were intact around the Teflon rim but had become detached from the annulus: the prosthesis was replaced. He was given 2 million units sodium penicillin and $1 \mathrm{~g}$. streptomycin daily for eight days following surgery.

He had an uneventful post-operative course, returned to work three months after operation, and has remained well since.

CASE 2 (C.B. 12535) A man aged 51 had a heavily calcified mitral valve replaced on 15 April 1965. He subsequently developed a right empyema from which was cultured a coagulase-positive Staphylococcus aureus. The empyema was drained but he continued to have a moderate pyrexia with shivering and headaches. Repeated blood cultures grew coagulasepositive Staph. aureus resistant to penicillin. Following treatment with sodium methicillin, $12 \mathrm{~g}$. daily, the fever subsided. He was discharged apyrexial five weeks after admission, antibiotics being suspended on discharge.

Five weeks later he was re-admitted in severe cardiac failure, and now was noted to have a soft mitral systolic murmur. On 4 August 1965 cardiac catheterization and cinéangiography revealed mitral regurgitation, the prosthesis displaying an abnormal movement. He was again pyrexial, and for this reason operation, despite negative cultures, was deferred. When deterioration became rapid, a decision was made to re-operate. He died suddenly on 6 August 1965, the morning for which surgery had been scheduled.

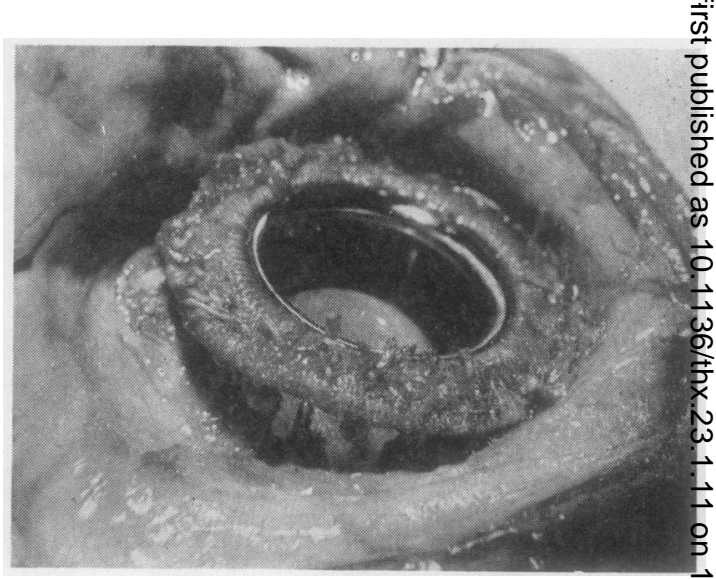

FIG. 1. Case 2. Detachment of prosthesis from annulus of mural leaflet.

At necropsy the prosthesis was found to be detached around most of its mural circumferenco (Fig. 1). The sutures, with knots intact, were hanging loosely from the Teflon rim. Intra-atrial thrombus was found on the attached margin of the prosthesis.

CASE 3 (D.T. 10590) A man aged 39 had closem mitral and aortic valvotomies carried out in 1960. OP 30 November 1964 he underwent aortic and mitraf valve replacement through a median sternotom $\vec{B}$ There was gross calcification of the mitral valve in the region of the lateral commissure and adjacene leaflet tissue, extending into fused, contracted chov dae. He was given 2 million units of sodium penicillin daily for 10 days following surgery.

He was discharged three weeks after operation buat returned two weeks later when a diagnosis of bacterial endocarditis was made following culture of $\frac{7}{3}$ coagulase-negative Staph. albus from the blood. He was treated with sodium methicillin, $12 \mathrm{~g}$. dail became febrile after four weeks, and remained so until discharge seven weeks after admission. Thrę months later he had a recrudescence of endocarditis the same organism being identified. A further cours of methicillin (12 g. daily) was given. During the next two months severe cardiac failure supervenew infection remained uncontrolled, and at this stage coagulase-positive Staph. aureus was isolated from the blood. Methicillin (12 g. daily) was continued withoue effect, and the response to massive penicillin dosage and later cephalosporin was equally disappointing On 22 June 1965 cardiac catheterization and cin angiography revealed severe mitral regurgitation with an exaggerated rocking movement of the mitrat prosthesis.

At operation on 23 June 1965 the left atrium wå explored through a left postero-lateral thoracotom The sternal and pericardial adhesions were dense and extremely vascular. The mitral prosthesis was foun to be detached along two-thirds of the mural annulus 
There were numerous vegetations and soft thrombus material attached to the annulus and adjacent Teflon rim. At the lateral commissure there was a projecting knob of calcium, $4 \mathrm{~mm}$. wide, abutting against the Teflon rim. This calcific knob proved to be situated in a remnant of contracted adherent chordae. It was apparent that regurgitation began in this area due to failure to seat the prosthesis accurately and then extended due to detachment of the prosthesis. The prosthesis was removed, and further débridement of the annulus was carried out before a new prosthesis was inserted, but the post-bypass bleeding from numerous adhesions and many coronary veins could not be controlled and the patient died.

\section{BACTERIAL ENDOCARDITIS WITH INTRA-ATRIAL THROMBOSIS}

CASE 4 (R.L. 14906) A man aged 21 had a closed mitral valvotomy via a left thoracotomy in 1959 . He was well for five years, after which he became progressively and severely disabled. Mitral valve replacement was carried out on 6 September 1965 via a right antero-lateral thoracotomy. The pericardium was densely adherent, and a heavily calcified valve was excised. Considerable difficulty was experienced in obtaining a satisfactory bed for the prosthesis in the region of the lateral commissure, where calcium extended into the myocardium.

Convalescence was delayed by an empyema which was drained, and he left hospital with a wound sinus five weeks after operation. The sinus closed rapidly and he remained well for five months but then developed recurrent joint pains. He was re-admitted three hours after the onset of acute left hypochondrial pain, for which a diagnosis of systemic embolism was made. On admission he was pyrexial with a remittent type chart reaching $39.5^{\circ} \mathrm{C}$. The prothrombin index was $28 \%$, haemoglobin 12 g. $/ 100 \mathrm{ml}$, and W.C.C. $18,600 /$ c.mm. Repeated blood cultures grew coagulasenegative Staph. albus sensitive to penicillin. He was treated with intravenous penicillin, 20 million units daily, but pyrexia continued. Four weeks after admission he developed pulmonary oedema and congestive cardiac failure: repeated electrocardiograms showed atrial tachycardia and ventricular ectopic beats. The chest radiographs following admission showed progressive cardiomegaly and pulmonary venous congestion (Fig. 2).

A diagnosis of intra-atrial thrombosis with obstruction of the prosthesis was made. Re-operation was considered despite what appeared to be prohibitive risks due to active endocarditis and the dense pericardial adhesions of previous post-operative infection. When temporary improvement occurred the idea was abandoned, but death occurred suddenly on 11 March 1966. At necropsy massive intra-atrial thrombosis obstructing the ball valve was found (Fig. 3). Septic infarcts were present in the brain, liver, spleen, kidney, and mesentery. It was noted that during his last illness the prothrombin index had been estimated on alternate days and had fluctuated between $28 \%$ and $62 \%$ : the majority of the estimations were below $50 \%$.

CASE 5 (P.W. 12428) A youth aged 20 with coarctation of the aorta had a grossly incompetent fenestrated mitral valve replaced on 2 April 1965.

He was given soluble penicillin, 2 million units daily, by intramuscular injection for five days after operation. On the sixth post-operative day he complained of dyspnoea and pleuritic pain in the left side. His temperature was $38.5^{\circ} \mathrm{C}$, and the spleen was palpable. Blood cultures initially were negative. Pyrexia and lassitude continued, and 16 days after operation further blood cultures grew coagulasepositive Staph. aureus. Intravenous therapy with methicillin, $16 \mathrm{~g}$. daily, and fusidic acid, $3 \mathrm{~g}$. daily, was begun on 28 April 1965. Anticoagulants had been started on 17 April 1965, and on 30 April 1965 the prothrombin index was $29 \%$. On 1 May 1965 acute pulmonary oedema developed and rapidly progressed to a fatal termination in a few hours. At necropsy the mitral valve prosthesis was covered and occluded by a mass of friable thrombus. Masses of Gram-positive cocci were seen on a smear of this thrombus and culture grew Staph. aureus. There was no evidence of mitral incompetence.

\section{INTRA-ATRIAL THROMBOSIS ASSOCIATED WITH SEPSIS} WITHOUT POSITIVE BLOOD CULTURE

CASE 6 (G.F. 18181) A man aged 46 was admitted on 9 December 1965 with severe symptoms and signs of mitral incompetence. Two months previously he had been admitted elsewhere with a diagnosis of pulmonary embolus and had been on anticoagulants since that time. On 16 December 1965 a thin incompetent valve was excised and replaced with a ballvalve prosthesis via a left thoracotomy. On the second post-operative day severe respiratory tract infection necessitated tracheostomy. Subsequently wound infection and empyema necessitated drainage of the chest on 24 December 1965. Anticoagulants, which had been suspended pre-operatively, were begun on 27 December 1965. Two days later the patient suddenly became decerebrate. A diagnosis of cerebral embolus and intra-atrial thrombosis was made, and treatment with heparin was begun, the prothrombin index at this time being $80 \%$. Deterioration continued and death occurred on 31 December 1965. At necropsy there was a large intra-atrial thrombus attached to the prosthesis, infarcts were present in the cerebrum, midbrain, and left kidney, and bilateral bronchopneumonia was present. No cultures were taken.

CASE 7 (M.B. 9103) A woman aged 44 had a mitral valve replacement on 7 September 1964. The valve was moderately calcified but was excised in toto; the tricuspid valve was also explored at the time but no procedure was performed: post-operative con- 


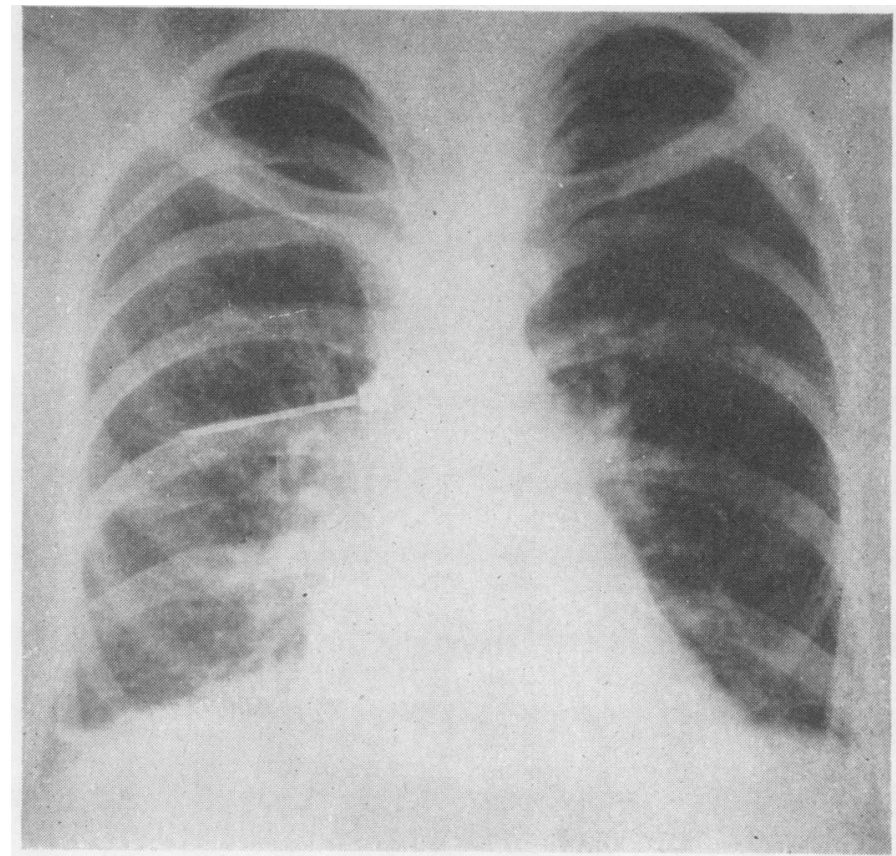

(a)

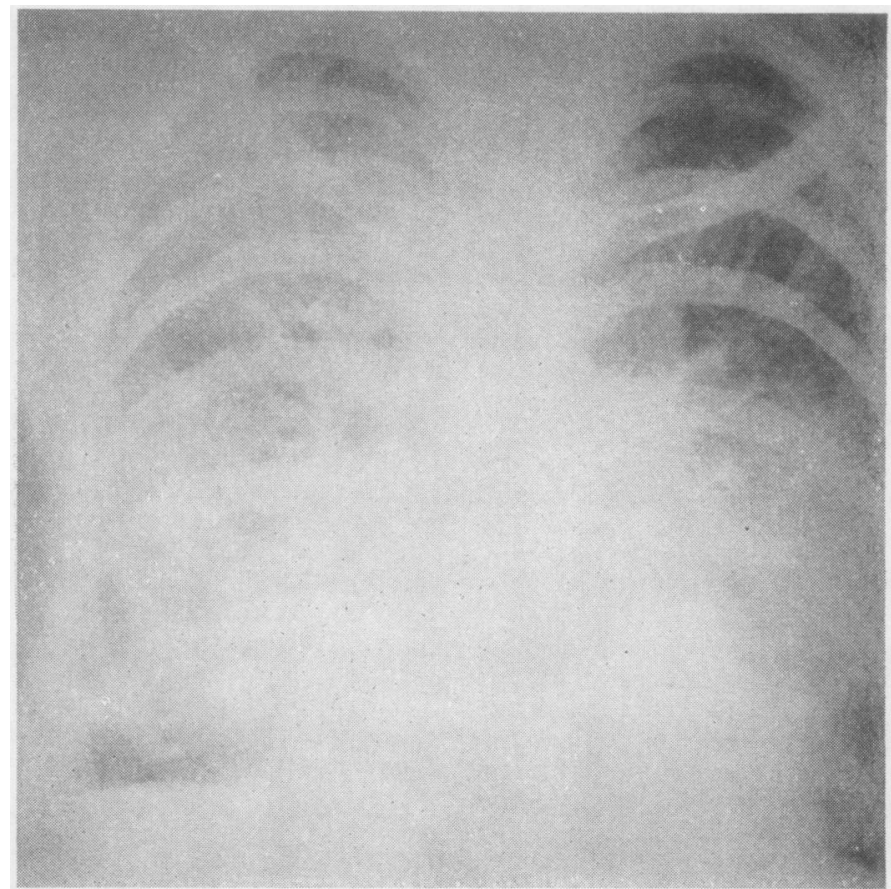

(b)

Figs 2a and b. Case 4. Progressive cardiomegaly and pulmonary congestion. 


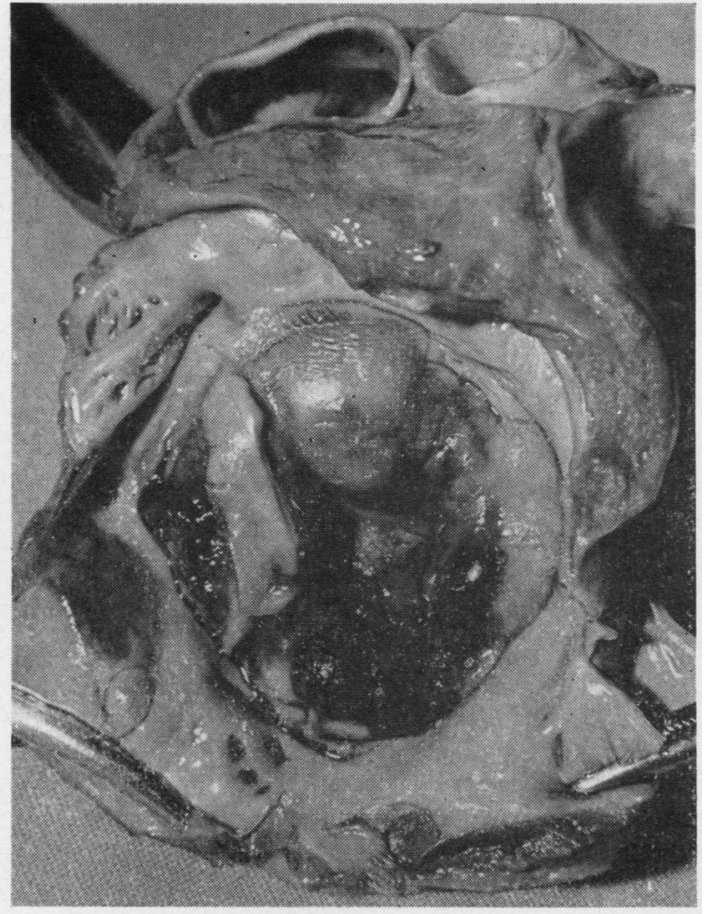

valescence was satisfactory. Ten weeks after operation she was re-admitted with a cerebral embolus and transient hemiparesis following a road accident in which she was thrown against the dashboard. There was no pyrexia during this three-week stay in hospital, and anticoagulant control was satisfactory. Tricuspid incompetence, however, was more severe. She was re-admitted on 2 January 1965 with severe tricuspid incompetence and cardiac failure, and a tricuspid valve prosthesis was inserted on 28 January 1965, though the left atrium was not explored at this operation. The patient was well until six hours postoperatively, when ventricular fibrillation suddenly occurred. Over the next five days 280 defibrillations were necessary, and during this period she became unconscious. A tracheostomy was performed as the tracheobronchial tree contained thick purulent secretions. Soluble penicillin, 2 million units daily, was commenced pre-operatively and continued until 14 February 1965. The state of consciousness slowly improved, but pulmonary infection remained severe. Anticoagulants, suspended before operation, were not recommenced because of the gross inflammation of the tracheobronchial tree. On 16 February 1965 a remittent pyrexia to $39.5^{\circ} \mathrm{C}$. began and continued until the patient died on 23 February 1965. No blood cultures were then. At necropsy the left atrium contained a thrombus occluding the mitral prosthetic orifice. No cultures were taken at necropsy. The

(a)

FIG. 3. Case 4. Thrombosis (a) from left atrial aspect; and (b) projecting into left ventricle, obstructing ball valve.

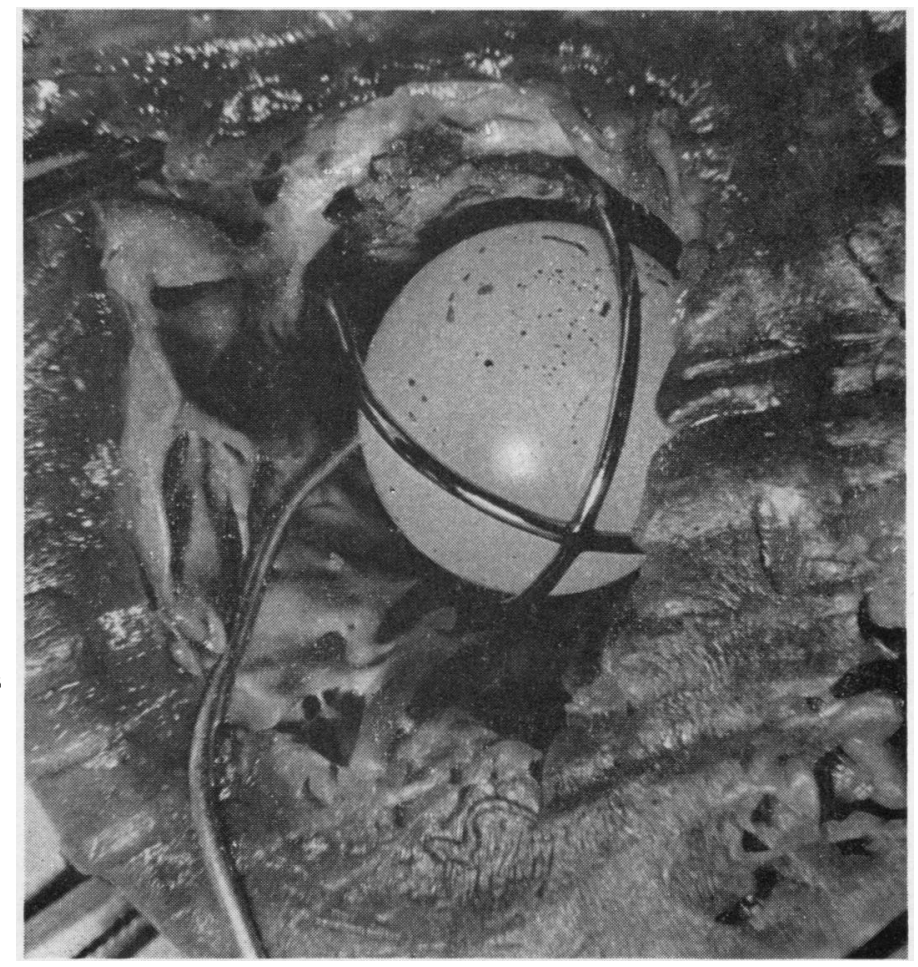


tricuspid valve prosthesis was normal and sutures appeared to be well clear of the conduction tissue. There was no obvious explanation for the numerous episodes of ventricular fibrillation other than the atrial thrombus.

CASE 8 (A.S. 7323) A man aged 42 was admitted in uncontrollable cardiac failure on 31 May 1964. In 1962 an open mitral annuloplasty had been performed elsewhere. This had been followed by a most complicated post-operative course with anuria requiring dialysis, chest and urinary tract infections, empyema, wound dehiscence, and pulmonary embolism. On 25 June 1964 a fibrosed incompetent mitral valve was excised and replaced with a ball-valve prosthesis via a right antero-lateral thoracotomy. His immediate post-operative condition was good, but on the third day he became hypotensive and developed a consolidated right upper lobe, for which tracheostomy was necessary. The sputum was thick and purulent and culture grew Pseudomonas pyocyanea. Soluble penicillin, 2 million units daily, started before operation, was continued. Oliguria occurred: peritoneal dialysis was begun on the sixth day and resulted in a satisfactory diuresis on the eighth post-operative day. There was no pyrexia at this time and anticoagulants had not been given. The wound became infected and several subcutaneous collections of pus were evacuated. Culture of this pus grew coagulase-positive Staph. aureus. On the eleventh post-operative day the patient, when apparently improving, suddenly collapsed and could not be resuscitated.

At necropsy the left atrium contained a large thrombus attached around the periphery of the prosthesis and obstructing the orifice. No cultures were taken. The right atrial appendage also contained antemortem thrombus. There was a large embolus obstructing the right pulmonary artery with infarction of the upper lobe.

\section{DISCUSSION}

The hospital mortality in 140 mitral replacements carried out in this unit was $12 \%$. This included four patients who underwent multiple valve replacement, and two patients operated upon in extremis because of bacterial endocarditis.

Bacterial endocarditis was proved by positive blood culture six times following replacement. Full information concerning the prosthesis was available on five occasions either from re-operation or necropsy examination. Mitral regurgitation, massive intra-atrial thrombosis, or both were present in each of these cases. In a further three cases, in which massive intra-atrial thrombosis was found at necropsy and appeared to be the major factor contributing to death, sepsis had been a feature and endocarditis a possibility. These facts emphasize the association which exists between infection following mitral valve replacement and the development of lethal complications.

We have attempted to develop and assess routine of management which will lessen the incidence of endocarditis and its associated com\& plications, and which will encourage earlier an more vigorous management of such complications. should they occur.

In this group only two patients were re-operated upon. One (case 1) is alive and well, the othe? (case 3) might have survived if an alternative approach to the valve, avoiding the adhesions of previous surgery, had been used. Case 2, in the light of present experience (Windsor and Shanahan, 1967), should certainly have had a furthe $\overrightarrow{5}$ operation. The other patients (cases $4,5,6,7$, and 8) all died, but the local lesion was amenable te correction either by removal of the thrombus of replacement of the prosthesis.

We have not removed thrombus from a pros thesis as a definitive procedure, but we believe thate to do so is feasible. In the two patients in whondo re-operation was performed for regurgitation (cases 1 and 3) friable thrombus and vegetation? had to be removed in the process of replacing the prosthesis. This experience indicates that replaced ment of an infected prosthesis with or withouf thrombus and vegetations is a practical procedure

Our experience in operating in the presence of bacterial endocarditis (Windsor and Shanahan? 1967) where vegetations were present also indi cates that infection can be controlled provided the nidus is removed and an adequate antibiotie regime is used.

Mitral REgurgitation In cases 1 and 2 thes detachment of the prosthesis was due to infection In case 1 cardiac catheterization and cinéangio graphy one year after surgery and two months before the onset of endocarditis failed to reveab regurgitation. In case 2 clinical evidence of endo carditis preceded that of regurgitation.

Local factors likewise influence the association by predisposing to infection. Failure to remove a calcific remnant at the lateral commissure resulted in faulty seating of the prosthesis in case 3. This undoubtedly acted both as a site for the commencement of regurgitation and as a nidus foe infection. In case 9 (Table) calcific remnants were strongly suspected as the basis for the endo? carditis (Windsor and Seldon, 1964).

Residual calcium in the annulus has constitute a hazard only if it prevented accurate seating of the prosthesis. It is, on occasion, impossible toD remove all the calcium. To do so in the region of the lateral commissure can endanger the circum 
flex artery or lead to atrioventricular dehiscence with resulting haemorrhage or false aneurysm.

In all three cases the prosthesis exhibited the abnormal rocking movement described by Björk and Björk (1966).

INTRA-ATRIAL THROMBOSIS That intra-atrial thrombosis occurred to some degree in all patients with bacterial endocarditis and has been associated with sepsis in three other patients in the series indicates that the principal predisposing factor is infection. Blundell and McGoon (1964) drew attention to this association. They reported massive fatal thrombus formation on an aortic ball valve in a calf. Blood cultures in this animal were negative but the thrombus contained numerous colonies of Gram-positive cocci. Hughes (1965), in a review of the complications reported following mitral valve replacement, made reference to fatal obstruction of the prosthesis by thrombosis in two patients, and suggested that, if this complication occurred, bacteriological examination of the thrombus and adjacent tissues be made prior to contamination at necropsy.

In our series of patients atrial thrombosis occurred early in the post-operative period in cases 5,6 , and 8 , but in cases 4 and 7 it did not present for many months. We believe that in these latter cases the basis for thrombosis was laid down in the early post-operative period. Anticoagulant therapy appeared to be adequate in cases 4 and 5 but did not prevent the complication. In the other three cases it was inadequate. In cases 6 and 7 anticoagulants, which had been in use prior to operation, were suspended afterwards, for reasons which seemed justified at the time. We now believe that, when infection is present, every effort should be made to institute early and adequate anticoagulant therapy and to maintain it, in spite of apparent contraindications.

The diagnosis of intra-atrial thrombosis is difficult, especially in the early post-operative period. In cases 5 and 8 it was completely unsuspected and even in retrospect we believe it was unrecognizable. In case 7 it was suspected, and in cases 4 and 6 a diagnosis was made after the occurrence of emboli. In case 4 additional clinical features made a diagnosis of prosthetic valvular obstruction possible. These were the symptoms and signs of pulmonary oedema and congestive cardiac failure, supra-ventricular tachycardia, ventricular ectopic beats, and a chest radiograph (Fig. 2) showing typical changes of pulmonary venous congestion.

Cinéangiography was not done in any of these patients with massive intra-atrial thrombosis.
Retrospective study of accurate cinéangiograms of patients from within whose left atria we have removed large amounts of clot at the time of valve replacement lead us to conclude that this investigation often fails to detect intra-atrial thrombosis. For this reason we are not hopeful of it being of value in detecting post-operative intra-atrial thrombosis. Furthermore, it is quite possible that left heart catheterization is contraindicated in the presence of intra-atrial thrombosis.

Diagnosis will largely hinge on a high degree of suspicion in a patient who has had a history of sepsis or pyrexia and in whom abnormal symptoms and signs are present.

The unpredictability of the event is well illustrated by case 5 , in which uncomplicated surgery was followed by infection and massive thrombosis. It can only be explained by the introduction of infection at operation.

ANTIBIOTICS Antibiotic therapy for patients undergoing mitral or aortic valve replacement was not standardized in this Unit until January 1966. Our first three replacements in March 1963 were not given antibiotics; then a series of 30 were given sodium methicillin, $6 \mathrm{~g}$. per day for 10 days, followed by oral sodium cloxacillin for an indefinite period. The next 100 cases were given 2 million units of penicillin per day, combined, if the need appeared to have arisen, with various other antibiotics.

Over this period there were, in addition to the cases reported here, four infections following aortic valve replacement in a series of 100 cases. A nidus of infection was present in three. In the fourth unexplained infection led to death due to massive thrombosis.

The causative organism in each of the cases reported was either coagulase-negative Staph. albus or coagulase-positive Staph. aureus (Table). Each occurred in three cases. These organisms, although occasionally insensitive in vitro, are undoubtedly on most occasions sensitive in vivo to the bactericidal action of massive intravenous dosage of soluble penicillin and methicillin (cases 1,2 , and 3 ).

The cases presented in this paper all had different post-operative antibiotics. When bacterial endocarditis developed, various combinations of methicillin, penicillin, fusidic acid, cephalosporin, and steroids were used.

In January 1966 a decision was made to standardize antibiotic therapy. Since that time the following regime has been used (Amoury, Bowman, and Malm, 1966): 
1. Procaine penicillin, $1,200,000$ units, sodium methicillin, $4 \mathrm{~g}$., and streptomycin, $0.5 \mathrm{~g}$., are given 24 hours prior to surgery.

2. For two weeks following surgery, potassium penicillin, 20,000,000 units, and sodium methicillin, $12 \mathrm{~g}$., are given daily through a right subclavian vein catheter. Streptomycin, $1 \mathrm{~g}$. daily for six days, is given unless there is concern regarding renal function.

3. At the end of two weeks the cases are divided into two groups. One is given oral sodium cloxacillin, $2 \mathrm{~g}$. daily, for three months. The other receives no antibiotics.

This regime was adopted for the following reasons :

(a) to obviate haphazard antibiotic therapy as can easily occur when many attendants are concerned with any one case ;

(b) because of the tendency for haphazard therapy to mask infection, to cause negative blood cultures, and thereby to delay adequate therapy ;

(c) because we believe that prophylactic antibiotics in large doses are of value ;

(d) because of the incidence of endocarditis following wound infection (cases 2 and 4);

$(e)$ because of the unpredictability of intra-atrial thrombosis and the difficulty of its recognition (case 5) ;

$(f)$ because of the impossibility of maintaining sterile conditions in a modern operating room and the ever-present risk of introducing infection (case 5).

Since adopting this regime there has not been one case of bacterial endocarditis or intra-atrial thrombosis in 120 valve replacements so managed. During this period seven patients underwent valve replacement who, because of drug sensitivity, were not given penicillin or methicillin. One of these, an aortic valve replacement for calcific aortic stenosis whose only antibiotic therapy was post-operative erythromycin, $2 \mathrm{~g}$. daily, developed Staph. albus endocarditis.
We suggest that this regime merely complements accurate surgical technique to avoid a nidus within the heart and the most stringent adherence to regulations designed to control infection in both the hospital and the operating room.

RE-OPERATION The question of re-operation in the patient with bacterial endocarditis and uncontrolled mitral regurgitation is no longer debatable. Surgery alone can rectify the haemodynamic state. Removal of a thrombus or nidus can control infection (case 1).

There can be little doubt that surgery is indicated in the management of intra-atrial $\vec{\overrightarrow{ }}$ thrombosis. Diagnosis is the difficulty. Infection is no contraindication, as persistence of a positive blood culture may be due to intra-atrial throm- $c$ bosis and the clue to its presence (cases 3, 4, and 5). It could be that persistence of infection constitutes the single most important indication for re-operation.

The timing of surgical intervention is a greater difficulty. It is obvious that, if the infection can be controlled before operation, then this is desirable. However, if, after a reasonable period of antibiotic therapy, infection or pyrexia is still present, surgery should probably not be delayed as death can occur suddenly from regurgitation (case 2), from emboli (case 6), from dysrhythmia (case 7), or from obstruction to the prosthesis (case 4).

\section{REFERENCES}

Amoury, R. A., Bowman, F. O., and Malm, J. R. (1966). Endocarditis associated with intracardiac prostheses: diagnosis, management and prophylaxis. J. thorac. cardiovasc. Surg., 51, 36.

Björk, L., and Björk, V. O. (1966). Cineradiography in the postoperative control of a Starr aortic valve prosthesis. Thorax, 21, 48.

Blundell, P. E., and McGoon, D. C. (1964). The fate of the StarrEdwards ball valve in the aortic area of calves. $J$. thorac. cardiovasc. Surg., 48, 704.

Hughes, R. K. (1965). Complications of Starr-Edwards mitral valve I replacement. Ibid., 49, 731 .

Windsor, H. M., and Seldon, W. A. (1964). Initial experiences in the replacement of the mitral valve. Med.J. Aust., 1, 112. and Shanahan, M. X. (1967). Emergency valve replacement o in bacterial endocarditis. Thorax, 22, 25 . 